\title{
Erratum to: Seismic fragility assessment of SMA-bar restrained multi-span continuous highway bridge isolated by different laminated rubber bearings in medium to strong seismic risk zones
}

\author{
M. Shahria Alam • M. A. Rahman Bhuiyan • \\ A. H. M. Muntasir Billah
}

Published online: 20 October 2012

C) Springer Science+Business Media Dordrecht 2012

\section{Erratum to: Bull Earthquake Eng DOI: 10.1007/s10518-012-9381-8}

Unfortunately several citations and references were omitted in this paper. They are listed below.

A citation to the following reference should have been added to the last sentence of the $3 \mathrm{rd}$ paragraph of Sect. 1:

Choi E, Nam TH, Cho BS (2005) A new concept of isolation bearings for highway steel bridges using shape memory alloys. Can J Civil Eng 32: 957-967.

A citation to the following reference should have been added to the 2 nd sentence of the 5 th paragraph of Sect. 1:

Hwang H, Liu JB, Chiu YH (2001) Seismic fragility analysis of highway bridges. MAEC report: project MAEC RR-4. Mid-America Earthquake Center, Urbana.

A citation to the following reference should have been added to the last sentence of the 5th paragraph of Sect. 1:

Nielson BG, DesRoches R (2007b) Seismic fragility methodology for highway bridges using a component level approach. Earthq Eng Struct Dyn 36: 823-839.

A citation to the following reference should have been added to the 2 nd sentence of the 1 st paragraph of Sect. 2:

The online version of the original article can be found under doi:10.1007/s10518-012-9381-8.

M. S. Alam $(\varangle) \cdot$ M. A. R. Bhuiyan · A. H. M. M. Billah

School of Engineering, University of British Columbia, Kelowna, BC V1V1V7, Canada

e-mail: shahria.alam@ubc.ca 
Mackie K, Stojadinovic B (2002) Optimal probabilistic seismic demand model for typical highway overpass bridges. In: 12th European conference on earthquake engineering. Paper no: 467.

A citation to the following reference should have been added to the last sentence of the 1st paragraph of Sect. 2:

Zhang J, Huo YL, Brandenberg SJ and Kashighandi P (2008) Effects of structural characterizations on fragility functions of bridges subject to seismic shaking and lateral spreading. Earthq Eng Eng Vib 7: 368-382.

A citation to the following reference should have been added to the 2 nd sentence of the 2 nd paragraph of Sect. 2:

Choi E, DesRoches R, Nielson BG (2004) Seismic fragility of typical bridges in moderate seismic zones. Eng Struct 26:187-199.

A citation to the following reference should have been added to the 3rd sentence of the 2 nd paragraph of Sect. 2:

Choi E, DesRoches R, Nielson BG (2004) Seismic fragility of typical bridges in moderate seismic zones. Eng Struct 26:187-199.

A citation to the following reference should have been added to the 1 st sentence of the 2 nd paragraph of Sect. 3:

Barndenbarg SJ, Zhang J, Kashighandi P, Huo Y, Zhao M (2011) Demand fragility surfaces for bridges in liquefied and laterally spreading ground. PEER Report 2011/01, Pacific Earthquake Engineering Research Center, College of Engineering, University of California, Berkeley.

A citation to the following reference should have been added to the 2nd sentence of the 2nd paragraph of Sect. 3:

Zhang J, Huo Y (2008) Fragility function of base isolated highway bridges. Structures Congress, 2008. October 2008, 1-17.

A citation to the following reference should have been added to the 5th sentence of the 2 nd paragraph of Sect. 3:

Zhang J, Huo Y (2009) Evaluating effectiveness and optimum design of isolation devices for highway bridges using the fragility function method. Eng Struct 31:1648-1660.

A citation to the following reference should have been added to the 6th sentence of Sect. 5.1:

DesRoches R, Choi E, Leon RT, Dyke SJ, Aschheim M (2004) Seismic response of multiple span steel bridges in Central and Southeastern United States. I: as built. J Bridge Eng 9(5):464-472.

A citation to the following reference should have been added to the 2 nd sentence of the 2 nd paragraph of Sect. 6: 
Karim KR, Yamazaki F (2001) Effect of earthquake ground motions on fragility curves of highway bridge piers based on numerical simulation. Earthq Eng Struct Dyn 30:18391856.

A citation to the following reference should have been added to the $3 \mathrm{rd}$ sentence of the 2 nd paragraph of Sect. 8:

Choi E, DesRoches R, Nielson BG (2004) Seismic fragility of typical bridges in moderate seismic zones. Eng Struct 26:187-199. 